\title{
N, P, K nutrition differentially affects the incidence and severity of the attack of pests and diseases in plants
}

\author{
Gómez-Trejo, Libia F. ${ }^{1}$; Hernández-Acosta, Elizabeth²; Peralta-Sánchez, Ma. Guadalupe ${ }^{3 *}$
}

${ }^{1}$ Departamento de Parasitología Agrícola. Universidad Autónoma Chapingo. Carretera MéxicoTexcoco km 38.5, Chapingo, Texcoco, Estado de México, México. ${ }^{2}$ Departamento de Recursos Naturales. Universidad Autónoma Chapingo. Carretera México-Texcoco km 38.5, Chapingo, Texcoco, Estado de México, México. ${ }^{3}$ Colegio de Postgraduados Campus Montecillo. Carretera México-Texcoco km 36.5, Montecillo, Texcoco, Estado de México, México.

*Corresponding author: mgperalta@colpos. $\mathrm{mx}$

\section{ABSTRACT}

Objective: To document and analyze relevant results reported on the relationships kept by the essential elements, nitrogen (N), phosphorus (P), and potassium (K) with biotic stress factors in higher plants.

Design/methodology/approach: A bibliographic analysis was carried out using keywords related to the concepts of nutrient relationship with phytopathogens, plant fertilization and nutrition and biotic stress. Subsequently, the most relevant articles on $\mathrm{N}, \mathrm{P}$, and $\mathrm{K}$ and their relationship with pests and diseases were selected and analyzed.

Results: The elements N, P, and K affect the development of pests on plants. Fertilization with $N$ tend to increase the presence of pests, while fertilization with $\mathrm{P}$ and $\mathrm{K}$ decreases it. However, this cannot be generalized for all crops or pests. Limitations/implications of the study: Research on the effects of $N, P$, and $K$ on the incidence of phytopathogens is limited and in most cases the mechanisms that determine such relashionship are not described.

Findings/conclusions: Fertilization with $N$ causes a higher incidence of pests and diseases in plants, while fertilization with $\mathrm{P}$ and $\mathrm{K}$ can contribute to reduce their incidence. However, due to the great diversity of responses, these statements are not applicable to all cases and depend on other factors such as the crop and the pest present in the agroecosystem. It is required to carry out studies that make it possible to clarify exactly how these essential elements influence the development of diseases in different crops, and thus be able to make nutrition recommendations in which limiting biotic factors are taken into account.

Keywords: plant nutrition-phytopathogens relationship; fertilization; plant nutrients; biotic stress

\section{INTRODUCTION}

\section{$C r \cap \mathrm{O}$ i is affected by different stress factors, both of biotic and abiotic nature (Calanca, 2017).

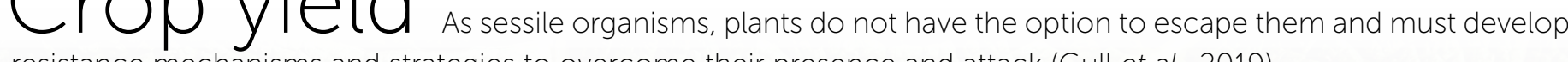 resistance mechanisms and strategies to overcome their presence and attack (Gull et al., 2019).}


Plants experience abiotic stress when the environmental conditions deviate from the optimal range for best growth and reproduction. Thus, for example, abiotic stress is stimulated by abnormal climatic conditions, such as temperatures that are too high or too low; persistent absence or excess of rain; high salinity, common in arid or semi-arid environments, where rainfall is too scarce to prevent the accumulation of ions in the soil and where irrigation is a secondary cause of salinization; excess or deficit of solar radiation; strong winds; and floods, among others (Calanca, 2017).

Biotic stress is caused by agents such as viruses, bacteria, fungi, nematodes, insects, arachnids, and weed species, which deprive the plant of nutrients or space and can cause its death (Gull et al., 2019). Yield losses from biotic stress factors are around $35 \%$, and these could increase under the imminent imbalance within agroecosystems that climate change has brought with it (Baillo et al., 2019). Given the aforementioned, different strategies have been sought for pest control, among which we can cite: cultural, mechanical, chemical, and biological methods, among others (Frank et al., 2018). For much of recent history, the method of choice for farmers to control pests has been the use of chemicals, due to its speed and low cost. However, this method has brought several consequences, including a reduction in biodiversity, a decrease in pollinating insect populations, as well as different effects on human health. Therefore, it is imperative to have an Integrated Pest Management (IPM) as a strategy to control populations of harmful organisms, which in turn reduces the negative impacts on the environment, economy, and public health. The IPM involves the use of various management methods, from prevention to evaluation of the implemented measures (Steiro et al., 2020).

The proper management of plant nutrition is a fundamental component for the success of a crop, and its correct implementation can decrease the negative impact of several biotic stress factors on crop growth, development, and productivity indicators. However, the proper integration of nutritional aspects with the IPM turns out to be a real challenge, since numerous factors intervene in this relationship, such as the environment, the genetics of the plant, and the pest in question (Feller et al., 2018).

In fact, the nutritional status of a plant can negatively or positively affect the severity of a pest attack. Thus, resistance or susceptibility of the plant to a disease, morphological and histological structures and properties, synthesis of defense compounds, and virulence and survival capacity of the pathogen are components that can be affected by plant nutrients; and the responses that have been recorded in different crops are diverse. A plant with nutritional deficiencies is less vigorous and more susceptible to attack by pests (Singh, 2015). However, the adequate supply of some nutrients can increase the severity of the attack of some pathogens (Veresoglou et al., 2013).

Therefore, the objective of this review was to document the relevant results reported about the relationships between nitrogen $(\mathrm{N})$, phosphorus $(\mathrm{P})$, and potassium $(K)$, essential elements in higher plants, and biotic stress factors.

\section{NITROGEN}

Nitrogen $(\mathrm{N})$ is an essential element, determining factor for the growth and development of plants (Alcántar et al., 2016). Its concentration in plant tissues ranges from 1.5 to $2.0 \%$ on a dry base. This element is required for the synthesis of different molecules and macromolecules such as amino acids, proteins, nucleotides, coenzymes, and chlorophyll (Singh, 2015). Of the total proteins in plants, $N$ represents about 16\% (Sun et al., 2020). The assimilation of $\mathrm{N}$ is related to key physiological processes such as photosynthesis, photorespiration, respiration, and the tricarboxylic acid cycle, among others (Sun et al., 2020).

\section{Interaction of $\mathbf{N}$ with pests}

In general, it has been established that $\mathrm{N}$ fertilization increases the incidence of pests and diseases in plants. $N$ increases succulent tissues, the concentration of amino acids in the apoplast, and improves the canopy of plants, in addition to delaying maturity (Singh, 2015). All these factors favor the incidence of pests (Sun et al., 2020).

Excess $\mathrm{N}$ can increase the incidence of biotrophic pathogens and have the opposite effect for necrotrophic ones (Sun et al., 2020). The application of high doses of $\mathrm{N}$ aggravates diseases caused by obligate pathogens, while mitigating those caused by facultative pathogens (Singh, 2015).

In addition to dose, the form of $\mathrm{N}$, or the ratio of ammonium $\left(\mathrm{NH}_{4}^{+}\right)$to nitrate $\left(\mathrm{NO}_{3}^{-}\right)$, has an effect on diseases. The severity of diseases such as take-all (caused 
by the fungus Gaeumannomyces graminis var. tritici) increases with the application of $\mathrm{NO}_{3}^{-}$and decreases with the supply of $\mathrm{NH}_{4}^{+}$. The effect can also be the inverse, for example, in cases of blackleg (bacterial wilt caused by the Gram-negative bacterium Ralstonia solani) and infections by various species of Fusarium (Singh, 2015; Sun et al., 2020).

On the other hand, $\mathrm{N}$ deficiency can influence the dispersion of virulence factors such as type III secretion systems (T3SSs) in bacterial pathogens or promote the accumulation of amino acids such as gammaaminobutyric acid (GABA) in the area of infection (Sun et al., 2020). GABA is a cell signaling molecule that prepares the plant for defense in the event of attacks by pathogens.

By applying high rates of nitrogen fertilization, there is a greater population of pests such as whiteflies, thrips, leafhoppers, and aphids. $\mathrm{N}$ is one of the most important factors in the development of herbivore populations. The application of nitrogen fertilizers tends to stimulate the preference of herbivores towards certain N-rich tissues, increases the supply of succulent tissues; and thus raising the survival, growth, reproduction, and population density of herbivores (Shah, 2017). A correct joint application of $K$ and $N$, keeping an adequate ratio between both, can be beneficial and prevent the development of insect pests (Bala et al., 2018).

\section{Role of nitrogen in the defense mechanisms of plants}

$\mathrm{N}$ is a key element in the construction of the defense system of plants. For example, this nutrient negatively affects the physical defenses, since when there is an excess of $\mathrm{N}$ fertilization, there is an increase in plant growth, but at the cost of the formation of lignin and the waxy cuticle, which makes the plants more susceptible to penetration by pathogens and insects. It can also negatively affect the synthesis of phytoalexins, secondary metabolites that can limit infection by pathogens. In some cases, $\mathrm{NO}_{3}^{-}$nutrition can increase the production of secondary metabolites such as phenols and flavonoids, and have positive effects on antimicrobial proteins. Increasing the supply of $\mathrm{N}$ can also generate greater enzymatic activity of chitinases and pathogenesis-related proteins (PRs). N also participates in the regulation of enzymes such as phenylalanine ammonium lyase (PAL), which catalyzes the synthesis of defense metabolites against pathogens such as t-cinnamic acid and p-coumaric acid. $\mathrm{N}$ also stimulates the activity of antioxidant systems in plants, which reduces damage to the cell membrane (Sun et al., 2020).

\section{PHOSPHORUS}

Phosphorus (P) is a nutrient with vital functions for plant growth and productivity. Its concentration in plant tissues ranges between $0.05 \%$ and $0.5 \%$ of the total dry weight of the plant. Although the P concentration in the soil is 2000 times higher than in the plant, its fixation in the form of aluminum/iron or calcium/magnesium phosphates makes it unavailable for absorption by plants. Therefore, plants frequently face problems of $\mathrm{P}$ deficiency in agricultural fields (Malhotra et al., 2018).

P is decisive in the metabolism of plants, as it is responsible for the formation of adenosine triphosphate (ATP) and phospholipids in the membranes. Furthermore, it plays a key role in the formation of sugar phosphates and several vital nucleotides and coenzymes in plants. It is important for energy transfer, cell division, proper growth, and yield (Singh, 2015).

\section{Interaction of $\mathbf{P}$ with pests}

The effect of $P$ on the incidence or severity of diseases is not consistent and depends on the crop and the pathogen in question. Proper $\mathrm{P}$ fertilization effectively reduces the severity and incidence of soil-borne diseases, such as Pythium root rot in wheat or common potato scab caused by Streptomyces spp. P also reduces diseases such as downy mildew, blue mold, blight, and tobacco leaf curl virus (TLCV) (Singh, 2015).

Phytophagous insects show a much higher P content than their host plants, which causes a mismatch that imposes limitations inherent to meeting the nutritional requirements of these pest organisms. When fertilizing with $P$, there may be positive and negative effects on the incidence and growth of insect pests (Bala et al., 2018). In cases of sucking insects such as aphids and leafhoppers, higher P levels are associated with a higher incidence of insects (Shah, 2017; Bala et al., 2018). For the leafminer Liriomyza trifolii, P also has a significant deterrent effect at high concentrations, decreasing the incidence of the insect pests (Facknath and Lalljee, 2005).

\section{Role of phosphorus in the defense mechanisms of plants}

In potatoes, P can reduce the incidence of pests through the synthesis of different secondary metabolites such 
as phenols and terpenes. Phenolic compunds can interfere with the digestion, growth, enzyme activity, and cell division processes of insect pests. Furthermore, terpenes interfere with neuronal activity and block phosphorylation in insects. $\mathrm{P}$ participates in the accumulation of lignins and tannins that act as barriers that deter different pests (Bala et al., 2018). Inorganic phosphate (Pi) deficiency induces the jasmonic acid (JA) pathway, thus improving plant defenses against insects (Khan et al., 2016).

\section{POTASSIUM}

Potassium $(K)$ is involved in a long list of cellular processes. Unlike other important macronutrients, $K$ is not incorporated into organic matter, but remains as a soluble ion in cell sap, contributing up to $10 \%$ of dry organic matter (Ragel et al., 2019). It acts as an activator of different enzymes, in addition to playing a very important role in protein synthesis, stomatal opening and closing, photosynthate translocation, and root growth (Singh, 2015). Consequently, it is an essential element for plants that affects a series of physiological and biochemical processes that are involved in their resistance to biotic and abiotic stress factors (Wang et al., 2013).

\section{Interaction of $\mathrm{K}$ with pests}

The negative effects caused by phytophages and phytopathogens in plants decrease with $K$ fertilization (Amtmann et al., 2008). However, sometimes effects are not observed, or even $K$ fertilization can be beneficial for the pest (Wang et al., 2013). In general, K contributes to improving the defense responses of plants to attacks by fungi and insect pests. Contrastingly, $K$ fertilization does not show significant effects against diseases caused by bacteria and viruses (Davis et al., 2018). For some diseases, $K$ can interact negatively with other elements such as $\mathrm{Ca}$, causing an increase in diseases where Ca intervenes in the biology of the zoospore, such as collar rot and citrus gummosis (caused by the oomycete Phytophthora parasitica) (von Broembsen et al., 1997; Singh, 2015). For arthropods, $K$ fertilization has a negative effect on the development of populations of sternorrhynchans (aphids and leafhoppers), orthopterans, and coleopterans, while the effect is positive for the development of mites and lepidopterans (Shah, 2017; Bala et al., 2018).

\section{Role of potassium in plant defense}

The optimal supply of $K$ plays an important role in the development of diseases. In most plants with insufficient $K$, higher amounts of sugars and amino acids are generated and exuded, which favors the presence of diseases. Furthermore, $K$ deficiency significantly decreases the production of antifungal compounds at the site of infection (Singh, 2015).

Low levels of $K$ induce the synthesis of reactive oxygen species (ROS) and phytohormones such as auxins, ethylene, and jasmonic acid (JA), which causes greater tolerance to stress induced by both biotic and abiotic stress factors (Wang et al., 2013). Strengthening the defense system of the plant can be achieved by supplying sufficient levels of $K$ in the early growth stage and then decreasing this supply when reaching the terminal stage (Shabala and Pottosin, 2014)

\section{CONCLUSION}

The nutritional status of the plant is decisive in the activation of defense mechanisms against biotic stress factors. In the present work, various roles that the essential elements $N, P$, and $K$ play against pest organisms and causal agents of plant diseases were analyzed. In general, it is considered that overfertilization with $\mathrm{N}$ causes a higher incidence of pests and diseases in plants, while adequate fertilization with $P$ and $K$ results in their reduction. However, these statements are not applicable to all cases and depend on other factors such as the crop and the pest or pathogen present. Due to this variation in responses, more studies are needed to clarify exactly how these nutrients influence the development of pests in different crops, and thus be able to make plant nutrition formulas that take into account limiting biotic factors.

\section{REFERENCES}

Alcántar, G.G., Trejo-Téllez, L., \& Gómez-Merino, F. C. (2016). Nutrición de Cultivos (2da ed.). Montecillo, México: Colegio de Postgraduados.

Amtmann, A., Troufflard, S., \& Armengaud, P. (2008). The effect of potassium nutrition on pest and disease resistance in plants. Physiologia Plantarum, 133(4), 682-691. Doi: 10.1111/j.13993054.2008.01075.x

Baillo, E. H., Kimotho, R. N., Zhang, Z., \& Xu, P. (2019). Transcription factors associated with abiotic and biotic stress tolerance and their potential for crops improvement. Genes, 10(10), 771. Doi: 10.3390/genes10100771

Bala, K., Sood, A. K., Singh, V., \& Thakur, S. (2018). Effect of plant nutrition in insect pest management: A review. Journal of Pharmacognosy and Phytochemistry, 7(4), 2737-2742. 
Calanca, P.P. (2017). Effects of abiotic stress in crop production. In M. Ahmed, C. Stockle (Eds.), Quantification of Climate Variability, Adaptation and Mitigation for Agricultural Sustainability (pp. 1-21). Cham, Switzerland: Springer.

Davis, J. L., Armengaud, P., Larson, T. R., Graham, I. A., White, P. J., Newton, A. C., \& Amtmann, A. (2018). Contrasting nutrient-disease relationships: Potassium gradients in barley leaves have opposite effects on two fungal pathogens with different sensitivities to jasmonic acid. Plant, Cell \& Environment, 41(10), 2357-2372. Doi: 10.1111/pce.13350

Facknath, S., \& Lalljee, B. (2005), Effect of soil-applied complex fertiliser on an insect-host plant relationship: Liriomyza trifolii on Solanum tuberosum. Entomologia Experimentalis et Applicata, 115: 67-77. Doi: 10.1111/j.1570-7458.2005.00288.x

Feller, U., Kopriva, S., \& Vassileva, V. (2018) Plant nutrient dynamics in stressful environments: Needs interfere with burdens. Agriculture, 8(7), 1-6. Doi: 10.3390/agriculture8070097

Frank, S., Bradley, L. K., \& Moore, K. A. (2018). Integrated pest management. North Carolina Extension Gardener Handbook. NC State Extension, Raleigh, NC. [Accessed: 26-03-2021]. Retrieved from: http://content. ces.ncsu.edu/8-integrated-pest-management-ipm

Gull, A., Lone, A. A., \& Wani, N. U. I. (2019). Biotic and Abiotic Stresses in Plants. In A. B. De Oliveira (Ed.), Abiotic and Biotic Stress in Plants (pp. 1-6). London, United Kingdom: IntechOpen. Doi: 10.5772/intechopen. 85832

Khan, G. A., Vogiatzaki, E., Glauser, G., \& Poirier, Y. (2016). Phosphate deficiency induces the jasmonate pathway and enhances resistance to insect herbivory. Plant Physiology, 171(1), 632-644. Doi: 10.1104/pp.16.00278

Malhotra, H., Vandana, Sharma, S., \& Pandey, R. (2018). Phosphorus nutrition: Plant growth in response to deficiency and excess. In M. Hasanuzzaman, M. Fujita, H. Oku, K. Nahar, B. Hawrylak-Nowak (Eds.), Plant Nutrients and Abiotic Stress Tolerance (pp. 171-190). Singapore: Springer. Doi: 10.1007/978-98110-9044-8_7

Ragel, P., Raddatz, N., Leidi, E.O., Quintero, F.J. \& Pardo, J.M. (2019). Regulation of K+ Nutrition in Plants. Frontiers in Plant Science, 10(281), Doi: 10.3389/fpls.2019.00281

Shabala, S., \& Pottosin, I. (2014). Regulation of potassium transport in plants under hostile conditions: implications for abiotic and biotic stress tolerance. Physiologia Plantarum, 151(3), 257-279. Doi: 10.1111/ppl.12165

Shah, T. H. (2017). Plant nutrients and insects development. International Journal of Entomology Research, 2(6), 54-57.

Singh, D. P. (2015). Plant nutrition in the management of plant diseases with particular reference to wheat. In: L.P. Awasthi (Ed.), Recent Advances in the Diagnosis and Management of Plant Diseases (pp. 273-284). New Delhi, India: Springer. Doi: 10.1007/978-81-322-2571-3_20

Steiro, A. L., Kvakkestad, V., Breland, T. A., \& Vatn, A. (2020). Integrated pest management adoption by grain farmers in Norway: A novel index method. Crop Protection, 135, 105201. Doi: 10.1016/j.cropro.2020.105201

Sun, Y., Wang, M., Mur, L. A. J., Shen, Q., \& Guo, S. (2020). Unravelling the roles of nitrogen nutrition in plant disease defences. International Journal of Molecular Sciences, 21(2), 572. Doi: 10.3390/ijms21020572

Veresoglou, S. D., Barto, E. K., Menexes, G., \& Rilling, M. C. (2013). Fertilization affects severity of disease caused by fungal plant pathogens. Plant Pathology, 62(5): 961-969. Doi: 10.1111/ppa.12014

von Broembsen, S. L., \& Deacon, J. W. (1997). Calcium Interference with zoospore biology and infectivity of Phytophthora parasitica in nutrient irrigation solutions. Phytopathology, 87(5), 522-528. Doi: 10.1094/ PHYTO.1997.87.5.522

Wang, M., Zheng, Q., Shen, Q., \& Guo, S. (2013). The critical role of potassium in plant stress response. International Journal of Molecular Sciences, 14(4), 7370-7390. Doi: 10.3390/ijms14047370

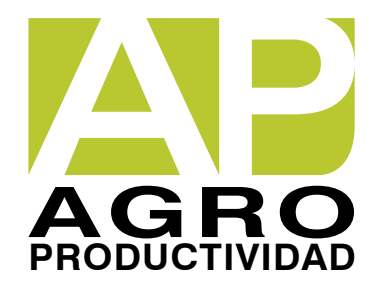

